\title{
Realization of reinforced concrete structures analysis with the account of physical and geometrical nonlinearity in computer program PRINS
}

\author{
Vladimir Agapov
}

Moscow State University of Civil Engineering, Yaroslavskoe shosse, 26, Moscow, 129337, Russia

\begin{abstract}
An algorithm of physically and geometrically nonlinear static analysis of structures by the finite element method is described, the distinguishing feature of which is the use of a full nonlinear stiffness matrix. This matrix is represented as the sum of five terms, namely, the stiffness matrix of the zero, first and second order, as well as matrices of initial displacements and initial stresses. When using modified Lagrange coordinates, the matrix of the initial displacements becomes a zero matrix. The calculation is carried out by a step-by-step method. Features of the application of this technique in the calculation of reinforced concrete structures are considered. The examples of static nonlinear analysis of reinforced concrete structures with the aid of program PRINS are given.
\end{abstract}

\section{Introduction}

The reinforced concrete structures analysis with account of physical and geometrical nonlinearities by finite element method was released in many computer programs, such as NASTRAN [1], ANSYS [2], ABAQUS [3], ADINA [4], DIANA[5] and others. In the most of these programs the flow theory is used and the task is solved by the step-by-step method. At that the equilibrium equations are written on each step of loading in the form [6-9]:

$$
\mathbf{K}_{\mathbf{j}}^{\mathbf{i}} \Delta \mathbf{u}_{\mathbf{j}}^{\mathbf{i}}=\mathbf{P}_{\mathbf{j}}-\mathbf{F}_{\mathbf{j}}^{\mathbf{i}-1}
$$

where $\mathbf{K}$ - tangent stiffness matrix, $\Delta \mathbf{u}$ - nodal displacements vector, $\mathbf{P}$ - vector of the externally applied nodal loads, $\mathbf{F}$ - vector of nodal point forces that are equivalent to the element stresses, $\mathrm{j}$ - step number, $\mathrm{i}$-iteration number.

In practice, three approaches are used to solving of the equation (1):

1) matrix $\mathbf{K}$ is recalculated on each iteration (Newton-Raphson method);

2) matrix $\mathbf{K}$ remains constant during the step (modified Newton-Raphson method); 
3) the inversed matrix $\mathbf{K}^{-1}$ is reconstructed on each iteration using the regularity in the changing of the displacement function gradient without of calculation of the new matrix $\mathbf{K}$ and its inversion (quasi-Newton method[10-17]).

It's obvious that Newton-Raphson method allows to reach the given tolerance for less number of iterations compared to modified Newton-Raphson, but it's not obvious, that total time of solution will be also less. As the convergence problem of iterative methods has the important meaning at the solution of the nonlinear equation systems of high order, the different methods of convergence acceleration have been suggested. Among them are the so called quasi-Newton methods mentioned above. In the computer finite element programs the BFGS (Broyden-Fletcher-Goldfarb-Shanno) method has found the greatest application (see, for example,[7]).

In spite of the successes achieved in the solving of nonlinear algebraic equation systems, the problem of nonlinear structural analysis can't be considered completely solved, and the development of alternative method is still relevant.

The method of reinforced concrete structures analysis with account of physical and geometrical nonlinearity and its realization in the program PRINS is described below. The samples of application of the program PRINS for analysis of some structures are given.

\section{Methods}

Nonlinear analysis of structures is carried out in the program PRINS by the step-by-step method. At that on each step of loading the next equation is formulated and solved [18]:

$$
\left[\mathrm{K}_{\mathrm{NL}_{0}}+\mathrm{K}_{\sigma}+\mathrm{K}_{\mathrm{NL}_{1}}+\mathrm{K}_{\mathrm{NL}_{2}}\right] \Delta \mathbf{u}=\Delta \mathbf{P}
$$

where $\mathbf{K}_{\mathrm{NL}_{0}}, \mathbf{K}_{\mathrm{NL}_{1}}, \mathbf{K}_{\mathrm{NL}_{2}}$ - the stiffness matrices of the zero, first and second orders, respectively; $\mathbf{K}_{\boldsymbol{\sigma}}-$ matrix of initial stresses; $\boldsymbol{\Delta} \mathbf{u}$ and $\mathbf{\Delta} \mathbf{P}-$ vectors of increments of nodal displacements and loads, respectively.

The matrices $\mathbf{K}_{\mathrm{NL}_{1}}$ and $\mathbf{K}_{\mathrm{NL}_{2}}$ depend on the current step displacements in the first and second degree, respectively. This dependence was obtained in [18] in an explicit form.

The matrix $\mathbf{K}_{\mathbf{N L}_{0}}$, whose elements are determined by the properties of the material, also depends on the step values of the displacements, - this dependence is determined by the law of deformation of the material, - but it is not possible to obtain this relationship explicitly. This matrix can be calculated at the beginning of the step, taking into account the physical properties of the material at the given instant of time, and under the same assumptions at the end of the step. We denote these matrices $\mathbf{K}_{0}$ and $\mathbf{K}_{1}$, respectively. Strictly speaking, the equation (2) should be rewritten in the form:

$$
\int_{\mathbf{u}_{b}}^{u_{e}} \mathbf{K}_{\mathbf{N L}_{0}} d u+\left[\mathbf{K}_{\mathbf{\sigma}}+\mathbf{K}_{\mathrm{NL}_{1}}+\mathbf{K}_{\mathrm{NL}_{2}}\right] \Delta \mathbf{u}=\Delta \mathbf{P},
$$

where $\mathbf{u}_{\mathbf{b}}$ И $\mathbf{u}_{\mathbf{e}}-\mathrm{e}$ the values of displacements at the beginning and at the end of the loading interval, respectively.

However, calculations based on formula (2) are practically impossible, since there is no analytic expression for $\mathbf{K}_{\mathbf{N L}_{0}}$, and the upper bound of the integration interval is unknown. Calculating the integral by the trapezoid rule, we obtain 


$$
\int_{\mathbf{u}_{b}}^{u_{e}} \mathbf{K}_{\mathbf{N L}_{0}} d u=\frac{1}{2}\left[\mathbf{K}_{\mathbf{0}}+\mathbf{K}_{\mathbf{1}}\right] \Delta \mathbf{u}=\left[\mathbf{K}_{\mathbf{0}}+\Delta \mathbf{K}\right] \Delta \mathbf{u},
$$

where $\Delta K=\frac{1}{\mathbf{2}}\left[K_{1}-K_{0}\right]$.

Substituting (4) in (3), we get:

$$
\left[\mathbf{K}_{0}+\Delta \mathbf{K}+\mathbf{K}_{\sigma}+\mathbf{K}_{\mathrm{NL}_{1}}+\mathbf{K}_{\mathrm{NL}_{2}}\right] \Delta \mathbf{u}=\Delta \mathbf{P} \text {. }
$$

Equation (5) is solved in the program PRINS by an iterative method of additional loading, which is equivalent of the modified Newton-Raphson method. In this case, equation (5) is written in the form

$$
\left[\mathbf{K}_{0}+K_{\sigma}\right]_{j} \Delta u_{j}^{(i)}=\Delta P_{j}-\left[\Delta K+K_{\mathrm{NL}_{1}}+K_{\mathrm{NL}_{2}}\right]_{j}^{(i-1)} \Delta u_{j}^{(i-1)}
$$

At the end of the iterative process, the total values of displacements and stresses at the end of the loading step are found by formulas:

$$
\mathbf{u}=\mathbf{u}_{0}+\Delta \mathbf{u} ; \sigma=\sigma_{0}+\Delta \sigma .
$$

Stress increments are calculated by formula:

$$
\Delta \sigma=C_{e p} \Delta \varepsilon
$$

where $\mathbf{C}_{\mathrm{ep}}$ is the elasto-plastic matrix of material characteristics. Detail description of the methods of derivation of this matrix for one- and two-dimensional reinforced concrete structures, realized in the program PRINS, is given in the works $[19,20]$.

Note that when plastic deformations and cracks formation are taken into account, it is necessary to analyze the stress state at each loading step and at each iteration and to correct the stresses using the stress-strain diagrams. This requires the carrying out of the process of equilibration of the structure.The equilibrium iterations is performed in the program PRINS in accordance with the formula (1), which acquires the form

$$
\left[\mathbf{K}_{0}+\mathbf{K}_{\sigma}\right]_{j}^{i} \Delta \mathbf{u}_{j}^{i}=\mathbf{P}_{j}-\mathbf{F}_{j}^{i-1}
$$

\section{Results}

To illustrate the possibilities of the proposed methodology the load-bearing capacity for two structures was investigated with the aid of program PRINS. Input data and results of analysis are given below.

\subsection{Analysis of prestressed reinforced concrete truss}

The analysis of the truss was carried out with the following input data (see Fig.1).

Panel length $d=3 \mathrm{~m}$, height $h=3 \mathrm{~m}$; cross section dimensions for all bars $20 \times 20 \mathrm{~cm}$, the bars reinforcement schemes are shown in Fig.2; heavy concrete of B20 class, nonprestressed reinforcement of class A400, prestressed reinforcement of class K1400 were used; the truss was loaded with concentrated forces $\mathrm{P}=25 \mathrm{kN}$ at the nodes of the bottom chord of truss. 


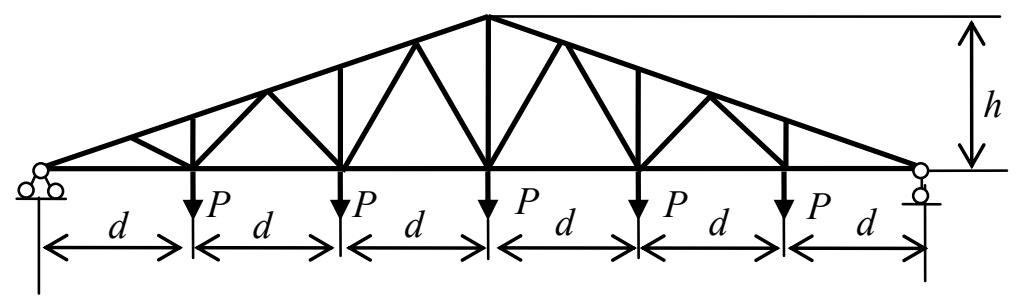

Fig.1. Design model of truss

The load was applied in steps. At the first step, the prestress was carried out by setting of the temperature effect on the prestressed reinforcement of the bottom chord. The stress diagram in concrete at the first step of loading obtained with the aid of developed program is shown in Fig.4. At subsequent steps, an external nodal load was applied with a multiplier, the value of which was assumed to be 0.05 for steps from 2 to 15 , and 0.025 for the remaining steps. The purpose of the analysis was to determine the ultimate load for the truss and to study its behavior during the loading process.

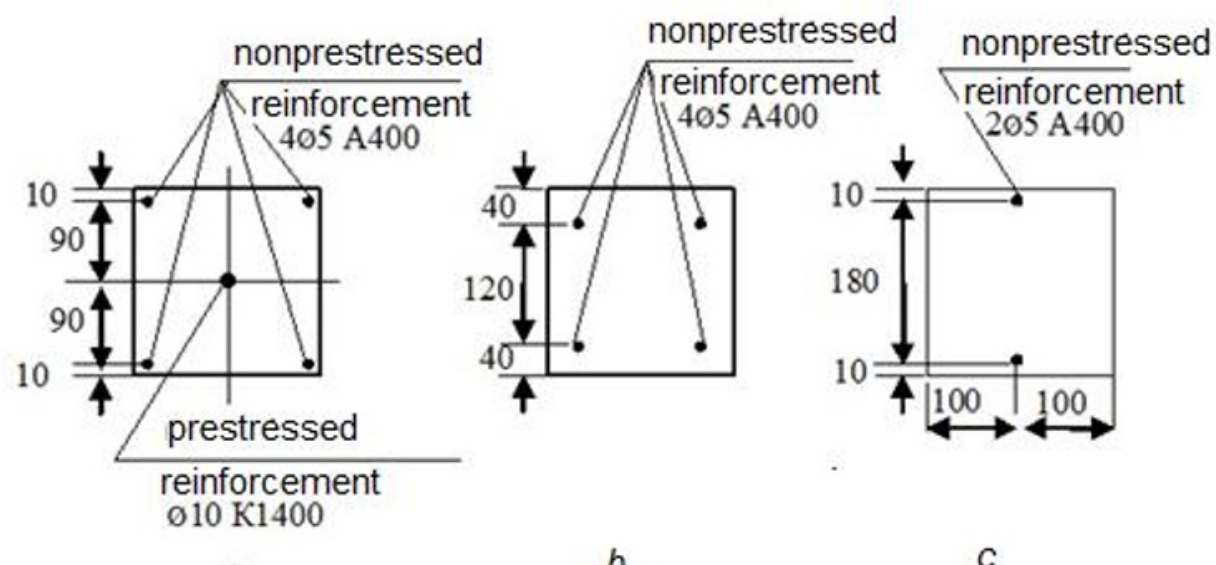

$a$

Fig.2. The bars reinforcement schemes: $a$ - bottom chord, $b$-top chord, $c$ - lattice

The destruction of the truss occurred at the 18th step with nodal load equal to $0.775 \mathrm{P}$. We give some of the analysis results that allow us to understand the causes of destruction.

Fig. 3 and Fig.4 shows the diagrams of concrete stresses and the stresses in nonprestressed reinforcement, respectively, at the 17th step of loading. It is seen from these figures that at the 17th step of loading the stresses in the concrete of the bars of the bottom chord and in the central vertical post become zero due to the cracking of the concrete, and the stresses in the armature of the central vertical reach the yield point. Consequently, at the 17th step the truss turns into a mechanism, and its further loading becomes impossible. 


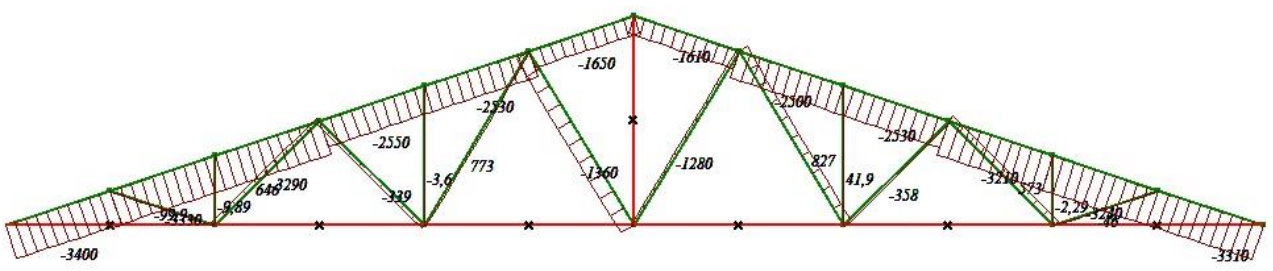

Fig.3.Stresses in concrete at 17th step of loading

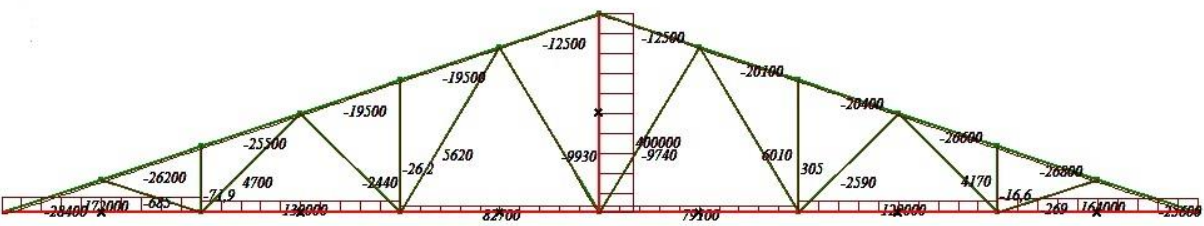

Fig.4. Stresses in nonprestressed reinforcement at 17th step of loading

Fig. 5 shows the diagram of the total values of the forces in the bars at the 17th step of loading.

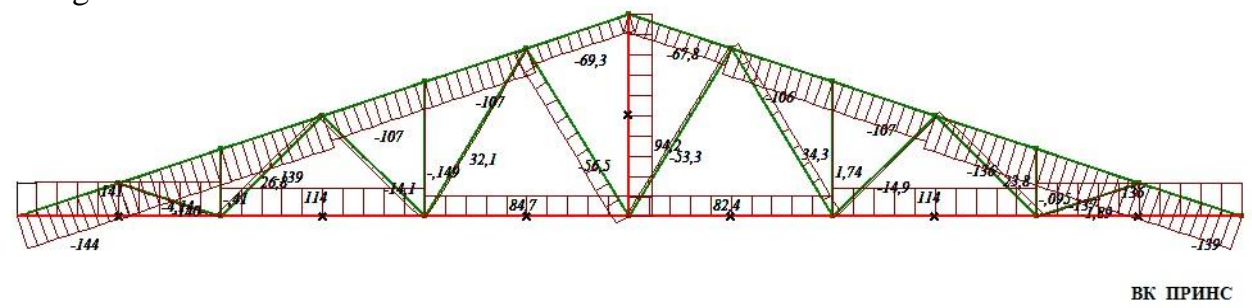

Fig.5. The diagram of the total values of the forces in the bars at the 17th step of loading

The deformed state of the truss at the 17th step of loading is shown in Fig.6.

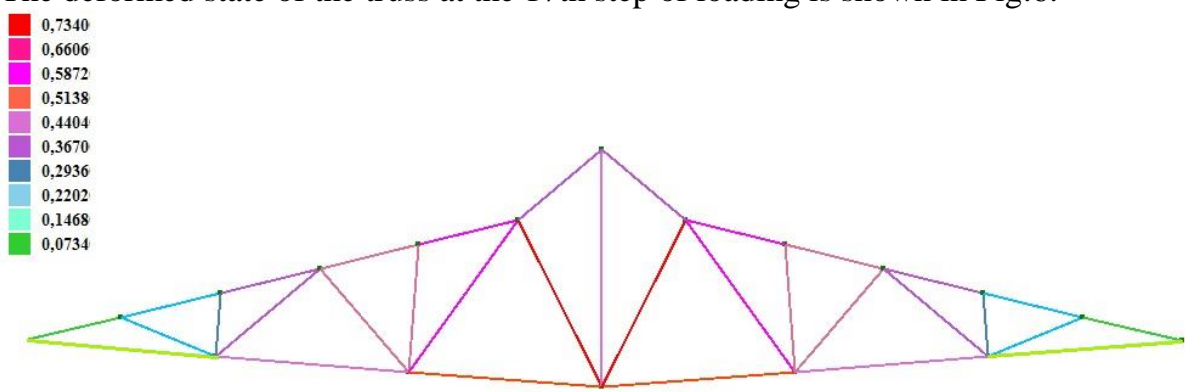

ВК ПРИНС

Fig.6. Deformed state of the truss at the 17th step of loading (displacement scale 1:1)

The sharp fracture of the top chord in Fig.8 is explained by the fact that when the vertical 9-10 breaks down, the central fragment of the truss 8-9-11-10 (see Fig.7) changes to a hinged quadrilateral in which it becomes possible the displacements of the nodes without deformation of the elements. 


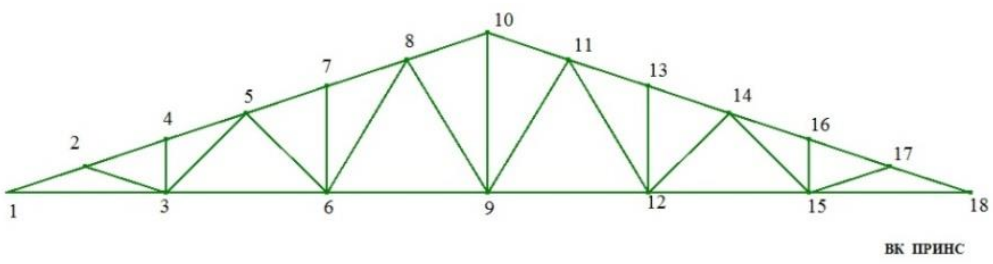

Fig.7 The numbering of the nodes

We note that when geometric nonlinearity is taken into account, the initially symmetric design scheme of the structure is somewhat distorted, which leads to a distortion of the symmetry in the stress-strain state.

Analysis of the causes of the destruction of the truss allows us to understand how to increase its load-bearing capacity. It is obvious that in this case it is necessary to strengthen the vertical 9-10 (Fig. 7). As calculations show, replacing the reinforcement of this bar from type "c" to type "b" (Fig. 2) leads to an increase in the maximum load to 1.275 P. At the same time the nature of the destruction does not change, which gives the foundation to suggest that the central vertical remains the weak link. Indeed, as the results showed, the yield stress as before is achieved primarily in the central bar.

Varying the dimensions of the cross sections and the reinforcement of the bars, and, possibly, the scheme of the truss, it is possible to achieve a further increase in its bearing capacity.

\subsection{Analysis of reinforced concrete slab strengthened with composite fabric}

To be able to verify the reliability of the results obtained, the slabe, which was strongly extended in one direction and simply supported along short sides (Fig.8), was calculated.

For comparison, calculation of a slab without amplification by a composite was also performed.

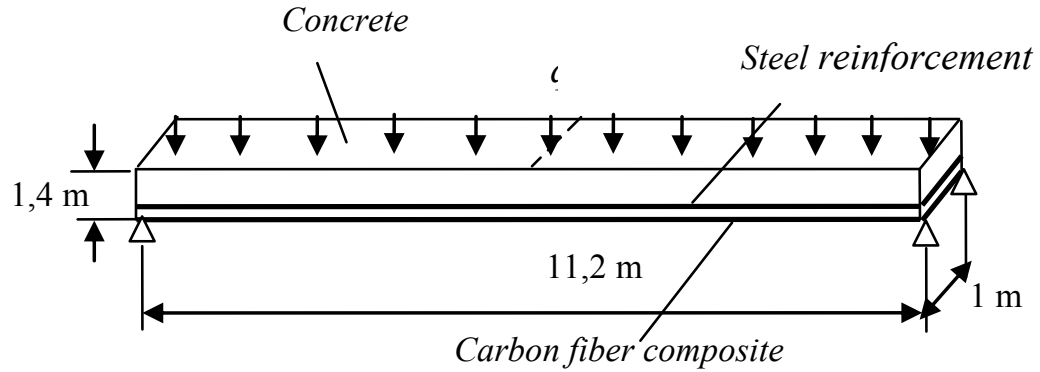

Fig.8.Reinforced concrete slab reinforced with composite fabric.

The finite element calculation scheme of the slab is shown in Fig.9. A non-uniform grid of finite elements with condensation to the middle of the span was used. The grid contains three groups of elements 1,2 and 3. The central group 3 consists of one line of elements.

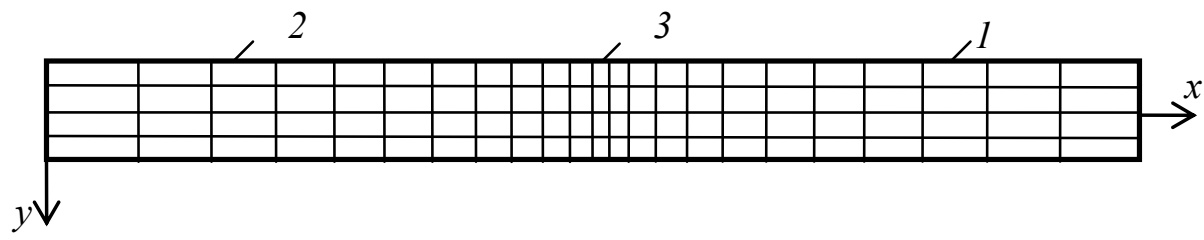

Fig.9. The finite element calculation scheme of the plate. 
The slab was partitioned by thickness into 29 layers. Layers 1, 12 and 29 are of zero thickness. Layer 12 is basic, and layers 1 and 29 are fictitious. Fictitious layers are introduced to enable the output of the stresses on the lower and upper surfaces in the postprocessor. The thicknesses and materials of the layers are given in Table 1.

Table 1. Layer characteristics.

\begin{tabular}{|c|c|c|}
\hline Layer number & Thickness, sm & Materials \\
\hline $2-11$ & 7 & Concrete \\
\hline $13-22$ & 6.25 & Concrete \\
\hline 23 & 0.21 & Steel \\
\hline $24-25$ & 3.5 & Concrete \\
\hline $26-28$ & 0.1 & Composite fabric \\
\hline
\end{tabular}

The following materials were used: concrete of B20 class, reinforcement of A400 class and composite fabric with unidirectional fibers. The following characteristics were taken for the fabric: modulus of elasticity $E_{K}=6,3 \times 10^{7} \mathrm{KPa}$, ultimate strength $R_{K}=7 \times 10^{5} \mathrm{~K}$ la , residual deformation $\varepsilon_{m}=2 \%$.

The slab was loaded with a uniformly distributed load of intensity $q=10 \mathrm{KPa}$. The load factors are given in Table 2.

Table 2. Load distribution by steps.

\begin{tabular}{|c|c|c|c|c|}
\hline $\begin{array}{c}\text { Step } \\
\text { numbers }\end{array}$ & $1-16$ & $17-32$ & $33-40$ & $\begin{array}{c}41 \text { and } \\
\text { onwards }\end{array}$ \\
\hline Load factors & 0.1 & 0.05 & 0.025 & 0.01 \\
\hline
\end{tabular}

Fig.10 and Fig.11 show the equilibrium state curves for a plate without and with composite fabric, correspondingly.

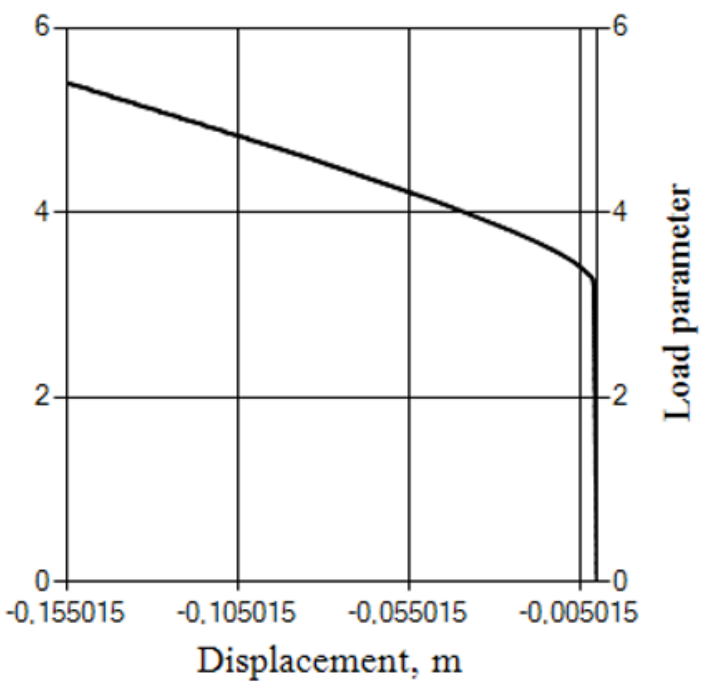

Fig.10. Equilibrium curve for the slab without composite fabric. 


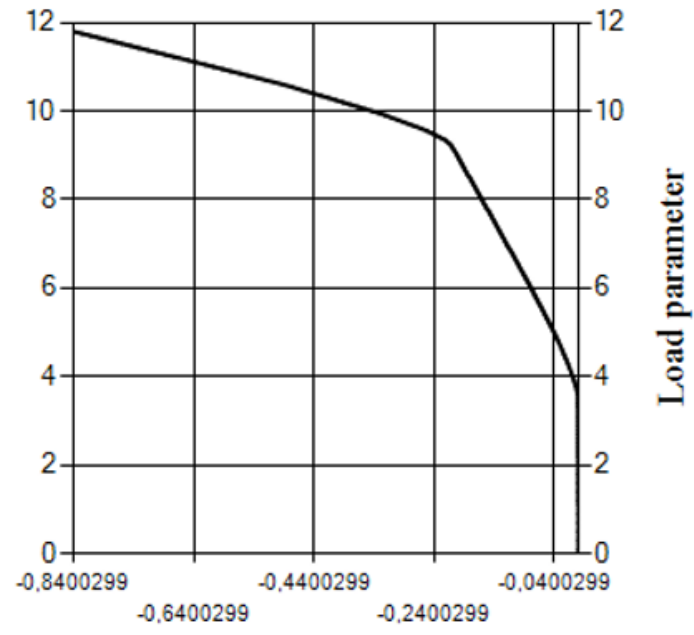

Displacement, $\mathrm{m}$

Fig.11. Equilibrium curve for the slab with composite fabric.

Fig.12 shows the values of the limiting moments for the slab without strengthening. The limiting state for a slab without reinforcement by composite fabric was reached at a load $q=53 \mathrm{\kappa} \Pi$ a , and for a reinforced slab - at $q=114 \mathrm{\kappa} \Pi$. The theoretical value of the bending moments for such loads is $831 \mathrm{kNm} / \mathrm{m}$ and $1788 \mathrm{kNm} / \mathrm{m}$, respectively.

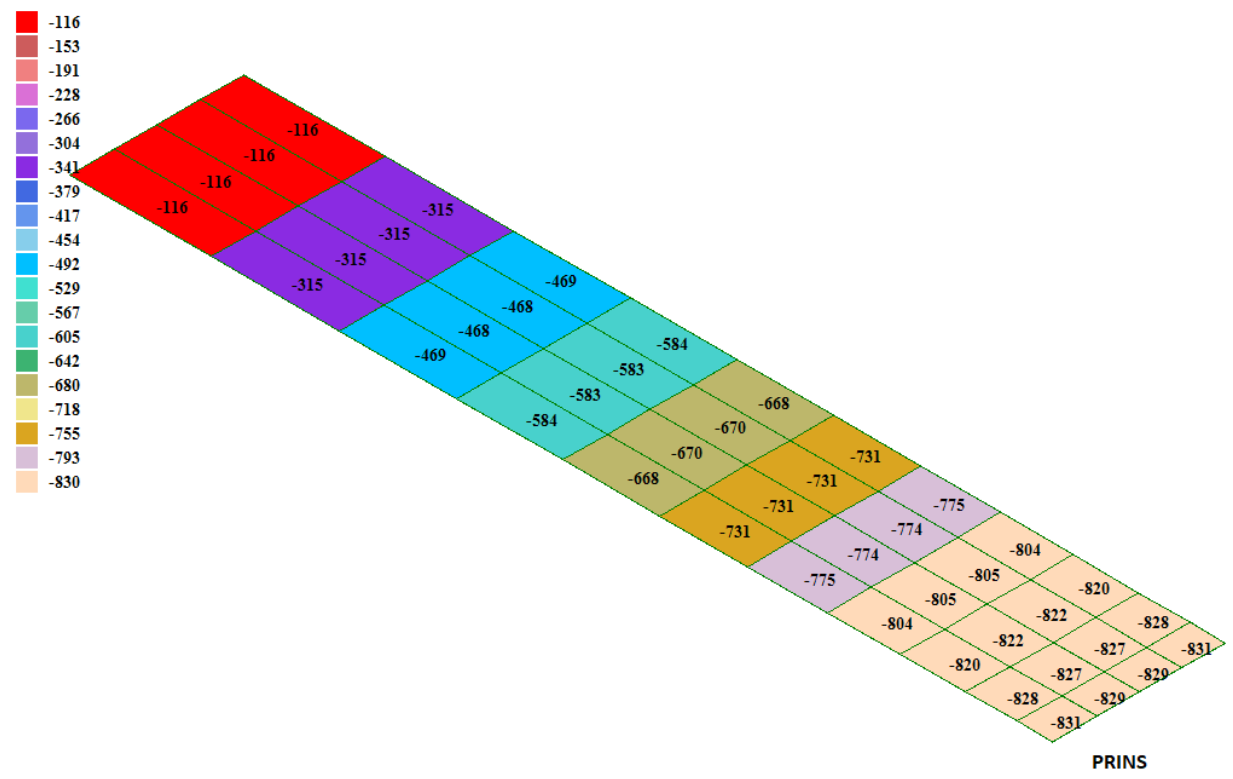

Fig.12. Limit bending moments for the slab without strengthening

The ultimate values of the moments found by the PRINS program were $830 \mathrm{kNm} / \mathrm{m}$ and $1790 \mathrm{kNm} / \mathrm{m}$, which is practically the same as the theoretical value.

With the adopted plate strengthening, the ultimate value of the bending moment increased by $116 \%$ compared with the original version. 
Fig.13 shows the penetration depth of a crack for a plate reinforced with a composite in a state prior to fracture.

When the number of composite layers increased twofold, the ultimate load reached into the value $\mathrm{q}=221 \mathrm{KPa}$, i.e. increased by $93.8 \%$ compared with the original variant.

As a result of the calculation, the forces and stresses in the composite fabric were also determined, the processes of crack formation in concrete and the plastic deformation of the reinforcement, etc. were investigated. The size of the article does not allow us to bring the obtained results in full.

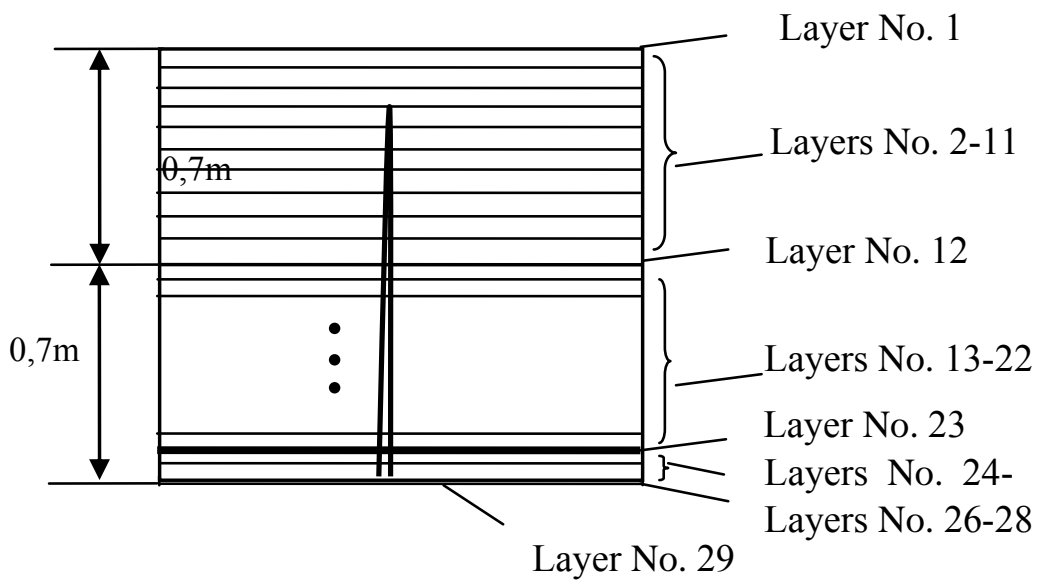

Fig.13. The depth of a crack for a plate reinforced with a composite.

\section{Conclusions}

The investigations carried out in the present study have shown that the method of physically and geometrically nonlinear calculation realized in the PRINS program gives the opportunity to analyze in detail the processes of deformation of reinforced concrete trusses and slabs with both traditional reinforcement and reinforcement with composite fabrics. Strict observance of the equilibrium conditions for the complex nature of the stressed state, noted in the solution of problems, attests to the reliability of the results obtained. The PRINS program is accessible to a wide range of specialists and can be useful in the calculation and design of reinforced concrete structures.

\section{References}

1. MSC NASTRAN 2016. Nonlinear User's Guide SOL 400 (MSC Software,2016)

2. ANSYS Theory Reference. Release 5.6 (Canonsburg, PA:ANSYS Inc, 1999)

3. ABAQUS 6.12. Theoretical manual (DS Simulia, 2012)

4. ADINA Theory and Modeling Guide (Elton Avenue Watertown, MA 02472 USA: ADINA R \& D, Inc,2003)

5. DIANA FEA User's Manual. Release 10 ( DIANA FEA bv, 2017)

6. O. C. Zienkiewicz, R. L. Taylor. The Finite Element for Solid and Structural Mechanics. Sixth edition (McGraw-Hill, 2005)

7. K. J. Bathe, E. L. Wilson. Numerical methods in finite element analysis (N.J.: PrenticeHall, 1976) 
8. M. A. Crisfield. Non-linear finite element analysis of solids and structures ( John Wiley \& Sons Ltd, 1977)

9. J. T. Oden. Finite elements in nonlinear continua (New York: McGraw- Hill Book Company, 1972)

10. C. G. Broyden. Math. Comp. 19577 (1967)

11. W. C. Davidon Math.Programming 91 (1975)

12. R. Fletcher A new approach to variable metric algorithms Ibid 13317 (1970)

13. R. Fletcher and M. J. D. Powell (1963) Comput. J. 6163 (1963)

14. D. Goldfarb. Sufficient conditions for the convergence of a variable metric method Optimization, Fletcher R. ed. (London:Academic Press, 1969)

15. D. F. Shanno. Conditioning of quasi-Newton methods for function minimization Math.Comp. 24647

16. J. E. Dennis, Jr. and J. J. More. SIAM Review, 19, No. 146 (1977)

17. H. Matthies and G. Strang. International Journal for Numerical Methods in Engineering 141613 (1979)

18. V. P. Agapov. Metod konechnyih elementov $v$ statike, dinamike $i$ ustoychivosti konstruktsiy (Moscow: Izd-vo ASV, 2005)

19. V. P. Agapov, R. O. Golovanov, K. R. Aidemirov. IOP Conf. Series: Earth and Environmental Science 90 (2017) 012018 (2017)

20. V. P. Agapov, R. O. Golovanov. Stroitel`naya mexanika inzhenerny`x konstrukcij i sooruzhenij 2 (2018) 